\section{PENGARUH MEKANISME KOMITE AUDIT TERHADAP MANAJEMEN LABA: STUDI EMPIRIS PADA PERUSAHAAN YANG MELAKUKAN MANAJEMEN LABA UNTUK MENGHINDARI KERUGIAN}

\author{
Eva Vajriyanti, Imam Subekti dan Abdul Ghofar \\ Fakultas Ekonomi dan Bisnis Universitas Brawijaya \\ Jalan Veteran, Malang, Jawa Timur 65145, Indonesia
}

\section{Abstract}

This study is conducted on companies in Indonesia during 2012-2015. This research is conducted to test whether manager performs earnings management to avoid negative earnings. This study also examines the effect of the mechanism of audit committee on earnings management. This study provides empirical evidence that manager performs earnings management to avoid negative earnings by increasing production costs and minimizing cash flow from operations. This study also provides empirical evidence that the mechanism of audit committee which consist of the size of audit committee, expertise of audit committee, as well as the audit committee meeting has no effect on earnings management by increasing production costs and minimizing cash flow from operations.

Keywords: Accrual earnings management, Mechanism of audit committee, Real earnings management.

\section{PENDAHULUAN}

Manajemen laba merupakan isu yang menarik banyak perhatian akademisi dan praktisi dalam beberapa tahun terakhir. Hal ini terjadi seiring dengan munculnya berbagai fenomena manajemen laba di berbagai perusahaan. PT. Kimia Farma, PT. Indofarma, dan PT. Katarina Utama merupakan contoh perusahaan di Indonesia yang melakukan manajemen laba. Kasus baru muncul dari PT. Inovisi Infracom Tbk (INVS) yang perdagangan sahamnya di suspensi selama empat bulan di tahun 2014. Hal ini terkait dengan temuan Bursa Efek Indonesia (BEI) terhadap adanya beberapa salah saji laporan keuangan pada tahun 2014, yang menyebabkan aset menjadi lebih tinggi (Anonim, 2015). Penelitian-penelitian sebelumnya, seperti Ferdawati (2009), Subekti (2012b), Lestari (2014), Vajriyanti et al. (2015), serta Aditama \& Purwaningsih (2016) membuktikan bahwa manajemen laba terjadi pada banyak perusahaan di Indonesia.

Studi-studi sebelumnya mengenai manajemen laba lebih banyak berfokus pada manajemen laba akrual. Graham et al. (2005) menemukan bukti bahwa manajer lebih menyukai manajemen laba riil dibandingkan dengan manajemen laba akrual. Penelitian Cohen \& Zarowin (2010) menemukan bahwa perusahaan yang sebelumnya melakukan manajemen laba akrual untuk meningkatkan kinerjanya, maka akan berubah melakukan manajemen laba riil pada periode setelahnya. Gunny (2010); Zang (2012); Zhu et al. (2015) juga menemukan bahwa kini perusahaan utamanya lebih memilih melakukan manajemen laba melalui aktivitas riil daripada melalui pengelolaan komponen akrual, namun manajer juga menggunakan kedua cara tersebut untuk mencapai target laba yang diinginkan.

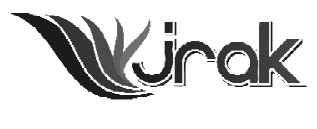
dan Keuangan

ISSN: 2088-0685 Vol. 6 No. 1, April 2016 Pp 801-810
Jurnal Reviu Akuntansi 


\section{Pengaruh Mekanisme Komite...}

Bukti empiris di Indonesia juga menemukan bahwa perusahaan publik di Indonesia cenderung melakukan manajemen laba riil daripada manajemen laba akrual untuk menghindari kerugian (Subekti, 2012b).

Graham et al. (2005) menduga bahwa penekanan manajer yang lebih besar pada manajemen laba riil disebabkan oleh keengganan manajer untuk menggunakan manajemen laba berbasis akuntansi, sebagai akibat dari skandal akuntansi Enron dan WorldCom. Zang (2012) juga menyebutkan bahwa manajemen laba akrual dibatasi oleh pengawasan pihak luar dan fleksibilitas. Manajemen laba akrual sering menjadi sorotan auditor, sedang manajemen laba riil kurang disoroti, sebab tindakan manajemen laba riil mirip dengan keputusan bisnis normal (Graham et al., 2005).

Manajemen laba merupakan isu yang kontroversial. Dechow \& Skinner (2000), Riduwan (2010), dan Febriyanti et al. (2014) mengungkapkan ada banyak pro dan kontra terkait manajemen laba. Pihak yang kontra menganggap bahwa tindakan manajemen laba sama saja dengan manipulasi laba, manajemen laba dapat mengurangi kualitas laba dan keandalan informasi dalam laporan keuangan, serta dapat menyesatkan stakeholders dalam mengambil keputusan. Manajemen laba merupakan fenomena yang menarik untuk diteliti, karena hal ini dapat merugikan perusahaan dan stakeholders. Manajemen laba bahkan dapat menyebabkan kebangkrutan, hal ini dibuktikan dengan runtuhnya perusahaan-perusahaan nomer wahid di Amerika Serikat akibat manajemen laba yang mengarah ke fraud. Enron Corp, Xerox Corporation, Walt Disney Company, dan Worldcom merupakan beberapa perusahaan yang mengalami kebangkrutan akibat terlibat skandal kejahatan korporat melalui manipulasi pembukuan (Irianto, 2003).

Berdasarkan hal-hal yang telah disebutkan sebelumnya, maka penelitian ini tertarik untuk menguji beberapa faktor yang dapat menurunkan manajemen laba. Fokus penelitian ini adalah perusahaan yang melakukan manajemen laba untuk menghindari kerugian. Hayn (1995), Burgstahler \& Dichev (1997), Roychowdhury (2006), dan Subekti (2012b) menemukan bahwa manajer melakukan manajemen laba untuk menghindarkan perusahaan dalam melaporkan kerugian. Pertama-tama penelitian ini menguji apakah manajer melakukan manajemen laba untuk menghindari kerugian. Selanjutnya penelitian ini menguji faktorfaktor yang dapat membatasi manajemen laba. Penelitian ini menggunakan mekanisme Komite Audit sebagai faktor yang menurunkan manajemen laba.

Teori Prospek mengungkapkan bahwa keputusan yang diambil terkait keuntungun atau kerugian didefinisikan secara relatif pada suatu titik acuan (reference point). Terkait tindakan manajer dalam menghindari kerugian, maka titik acuan yang digunakan adalah titik nol, seperti pada penelitian Hayn (1995), Burgstahler \& Dichev (1997), Roychowdhury (2006), dan Subekti (2012a). Manajer akan melakukan manajemen laba agar laba berada di atas titik acuan (titik nol). Tindakan ini dilakukan karena laba negatif mengindikasikan kinerja yang buruk, serta memberikan sinyal negatif kepada investor. Kerugian menyebabkan perusahaan harus menghadapi biaya transaksi yang lebih mahal dengan stakeholders (Burgstahler \& Dichev, 1997).

Komite Audit merupakan mekanisme terpenting dalam tata kelola perusahaan yang dapat menghambat manajemen laba, sebab Komite Audit merupakan bagian yang bertanggung jawab untuk memastikan akurasi dan reliabilitas laporan keuangan yang disediakan manajemen (Ayemere \& Elijah, 2015). FCGI (2001) menjabarkan mengenai tiga tanggung jawab Komite Audit. Pertama, memastikan laporan keuangan yang diterbitkan perusahaan telah mencerminkan keadaan sebenarnya. Kedua, bertanggung jawab terhadap tata kelola perusahaan guna memastikan bahwa perusahaan menjalankan usahanya sesuai dengan ketentuan hukum dan undang-undang, menjalankan bisnisnya secara etis, serta melakukan pengawasan dengan efektif terkait benturan kepentingan dan kecurangan yang terjadi di perusahaan. Ketiga, komite audit bertanggung jawab dalam pengawasan perusahaan. Wolnizer (1995) menyebutkan bahwa implementasi tanggung jawab Komite Audit dapat meningkatkan kredibilitas, reliabilitas, dan 
objektivitas laporan keuangan, meningkatkan akuntabilitas manajemen, mengurangi sifat oprtunis, serta meningkatkan efisiensi dan efektivitas pengendalian internal.

Melihat masih banyaknya kasus manajemen laba, ini membuktikan bahwa kehadiran Komite Audit tidak serta merta dapat membatasi manajemen laba (Ayemere \& Elijah, 2015). Keberadaan Komite Audit bukanlah jaminan untuk membatasi manajemen laba, tetapi bagaimana mekanisme Komite Audit yang berperan dalam membatasi manajemen laba dan meningkatkan kepercayaan stakeholders terkait laporan keuangan. Mekanisme Komite Audit tercermin melalui ukuran Komite Audit, jumlah rapat Komite Audit, independensi Komite Audit, serta keahlian Komite Audit (Alzoubi \& Selamat, 2012; Ayemere \& Elijah, 2015). Mekanisme Komite Audit yang efektif mampu meningkatkan kredibilitas, reliabilitas, dan objektivitas laporan keuangan, serta melindungi reputasi perusahaan dan kepentingan pemilik saham (Carcello et al., 2002).

Penelitian ini dapat menutup research gap terkait pergeseran manajemen laba, dari manajemen laba akrual ke manajemen laba riil. Penelitian ini dapat memberikan bukti mengenai tindakan manajemen laba yang dilakukan manajer untuk menghindari kerugian, serta memberikan bukti empiris yang lebih lengkap mengenai pemecahan masalah manajemen laba, dengan menguji beberapa variabel yang dapat menurunkan manajemen laba, yaitu mekanisme Komite Audit yang meliputi ukuran, independensi, keahlian dan rapat Komite Audit.

\section{PENGEMBANGAN HIPOTESIS}

\section{Manajer Melakukan Manajemen Laba untuk Menghindari Kerugian}

Hayn (1995), Burgstahler \& Dichev (1997), Roychowdhury (2006), dan Subekti (2012a) menemukan bahwa manajer melakukan manajemen laba untuk menghindari kerugian. Manajer akan mengelola laba negatif yang berada dibawah titik nol agar menjadi laba positif dan berada diatas titik acuan (titik nol) (Hayn, 1995; Burgstahler \& Dichev, 1997). Roychowdhury (2006) menemukan bukti bahwa sebagian besar perusahaan di Amerika Serikat melakukan manajemen laba dengan cara mengelola arus kas operasional, biaya produksi, dan beban diskresioner untuk menghindari kerugian. Subekti (2012a) menemukan bukti bahwa sebagian perusahaan di Indonesia melakukan manajemen laba dengan cara memperbesar arus kas operasional, memperbesar biaya produksi, memperkecil beban diskresioner, dan memperkecil long term discretionary accruals. Perusahaan-perusahaan tersebut melakukan manajemen laba untuk menghindari kerugian. Berdasarkan teori dan hasil penelitian-penelitian sebelumnya, maka hipotesis yang dapat disusun peneliti adalah sebagai berikut;

H1a : Manajer melakukan manajemen laba dengan memperkecil short term discretionary accruals untuk menghindari kerugian

H1b : Manajer melakukan manajemen laba dengan memperkecil long term discretionary accruals untuk menghindari kerugian

H1c : Manajer melakukan manajemen laba dengan memperbesar arus kas operasional untuk menghindari kerugian

H1d : Manajer melakukan manajemen laba dengan memperbesar biaya produksi untuk menghindari kerugian

H1e : Manajer melakukan manajemen laba dengan memperkecil beban diskresioner untuk menghindari kerugian

\section{Pengaruh Mekanisme Komite Audit terhadap Manajemen Laba}

Mekanisme Komite Audit diantaranya meliputi ukuran, rapat, independensi, dan keahlian Komite Audit. Alzoubi \& Selamat (2012) dan Ayemere \& Elijah (2015) menemukan bahwa ukuran, rapat, independensi, dan keahlian Komite Audit 


\section{Pengaruh Mekanisme Komite...}

804
Tabel 1. berpengaruh negatif terhadap manajemen laba. Hal ini menunjukkan bahwa mekanisme Komite Audit yang meliputi ukuran, rapat, independensi, dan keahlian Komite Audit berperan dalam menurunkan manajemen laba. Semakin besar ukuran Komite Audit diharapkan pengawasan semakin meningkat, sehingga dapat menurunkan manajemen laba. Komite Audit yang independen akan memberikan penilaian secara independen tanpa dipengaruhi oleh pihak lain. Komite Audit yang memiliki pengetahuan terkait keuangan dan akuntansi akan meningkatkan kinerja Komite Audit. Komite Audit yang lebih aktif bertemu akan lebih mungkin untuk melakukan tugas sesuai dengan kepentingan pemegang saham dan lebih berupaya dalam memantau integritas laporan keuangan. Berdasarkan teori dan hasil penelitian-penelitian sebelumnya, maka hipotesis yang dapat disusun peneliti adalah sebagai berikut;

H2 : Ukuran Komite Audit berpengaruh negatif terhadap manajemen laba

H3 : Independensi Komite Audit berpengaruh negatif terhadap manajemen laba

H4 : Keahlian Komite Audit berpengaruh negatif terhadap manajemen laba

H5 : Rapat Komite Audit berpengaruh negatif terhadap manajemen laba

\section{METODOLOGI PENELITIAN}

\section{Populasi dan Sampel}

Populasi penelitian ini adalah perusahaan yang terdaftar di Bursa Efek Indonesia (BEI) selama periode 2012-2015. Pengambilan sampel menggunakan metode purposive sampling. Tabel 1 menyajikan mengenai prosedur pemilihan sampel. Jumlah sampel yang digunakan dalam penelitian ini adalah 83 sampel, dengan jumlah pengamatan sebanyak 332 selama empat tahun.

\begin{tabular}{llc}
\hline No. & \multicolumn{1}{c}{ Kriteria } & Jumlah \\
\hline 1. & Perusahaan yang terdaftar di BEI tahun 2012 & 442 \\
2. & Perusahaan non-manufaktur & $(312)$ \\
3. & Perusahaan tidak terdaftar selama 4 tahun berturut-turut & $(11)$ \\
4. & $\begin{array}{l}\text { Perusahaan yang pelaporannya tidak dalam mata uang } \\
\text { Rupiah }\end{array}$ & $(26)$ \\
5. $\quad \begin{array}{l}\text { Perusahaan yang laporan tahunannya tidak lengkap dan tidak } \\
\text { dapat diakses }\end{array}$ & $(10)$ \\
Jumlah sampel & 83 \\
Jumlah pengamatan selama 4 tahun & 332 \\
\hline
\end{tabular}

\section{Jenis dan Metode Pengumpulan Data}

Penelitian ini menggunakan jenis data sekunder. Teknik pengumpulan data yang digunakan untuk memperoleh data sekunder adalah teknik pengumpulan data dari basis data. Data penelitian ini bersumber dari laporan tahunan yang diperoleh dengan mengakses situs BEI di www.idx.co.id.

\section{Definisi Operasional dan Pengukuran Variabel}

Penelitian ini mengukur manajemen laba dengan menggunakan lima proksi manajemen laba dalam penelitian Subekti (2012b), yaitu short term discretionary accruals (SHORTDA), long term discretionary accruals (LONGDA), abnormal cash flow of operation (ABNCFO), abnormal production cost (ABNROD), dan abnormal dicretionary expense (ABNDISCR). Model ini merupakan modifikasi dari model estimasi Kothari et al. (2005) dan Roychowdhury (2006). Satu penyesuaian dilakukan terhadap nilai total aset (1/At-1), dalam setiap model estimasinya Subekti (2012b) menggunakan nilai logaritma untuk total aset (1/Log. At-1). Hal ini dilakukan untuk menyesuaikan dengan perekonomian Indonesia, sehingga bisa men- 
dapatkan hasil analisis yang lebih baik. Berikut adalah model estimasi dari kelima proksi manajemen laba;

\begin{tabular}{|c|c|}
\hline ADTPD & $\begin{aligned}= & \text { STACCi,t/TAi,t }-1-[\eta 1(1 / \log \mathrm{TAi}, \mathrm{t}-1)+\eta 2((\Delta \mathrm{REV} / \Delta \mathrm{REC}) / \mathrm{TAi}, \\
& 1)+\eta 3(\mathrm{INCt} / \mathrm{TAi} \mathrm{t}-1)]\end{aligned}$ \\
\hline & $\begin{aligned}= & \text { LTACCi,t/TAi,t }-1-[\omega 1(1 / \log \text { TAi,t }-1)+\omega 2(\mathrm{PPEi}, \mathrm{t} / \mathrm{TAi}, \mathrm{t}-1)+\omega 3 \\
& (\mathrm{INTi}, \mathrm{t} / \mathrm{TAi}, \mathrm{t}-1)+\omega 4(\mathrm{INCt} / \mathrm{TAi}, \mathrm{t} 1)]\end{aligned}$ \\
\hline & $=\mathrm{CFOt} / \mathrm{At}-1-[\alpha 1(1 / \log \mathrm{At}-1)+\beta 1(\mathrm{St} / \mathrm{At}-1)+\beta 2(\Delta \mathrm{St} / \mathrm{At} 1)]$ \\
\hline & $\begin{aligned}= & \operatorname{PRODt} / \mathrm{At}-1-[\alpha 1(1 / \log \mathrm{At}-1)+\beta 1(\mathrm{St} / \mathrm{At}-1)+\beta 2(\Delta \mathrm{St} / \mathrm{At}-1)+\beta 3 \\
& (\Delta \mathrm{St}-1 / \mathrm{At}-1)]\end{aligned}$ \\
\hline & $=$ DISCRt $/$ At $-1-[\alpha 1(1 / \log$ At -1$)+\beta 1(\mathrm{St} / \mathrm{At}-1)]$ \\
\hline
\end{tabular}

Keterangan:

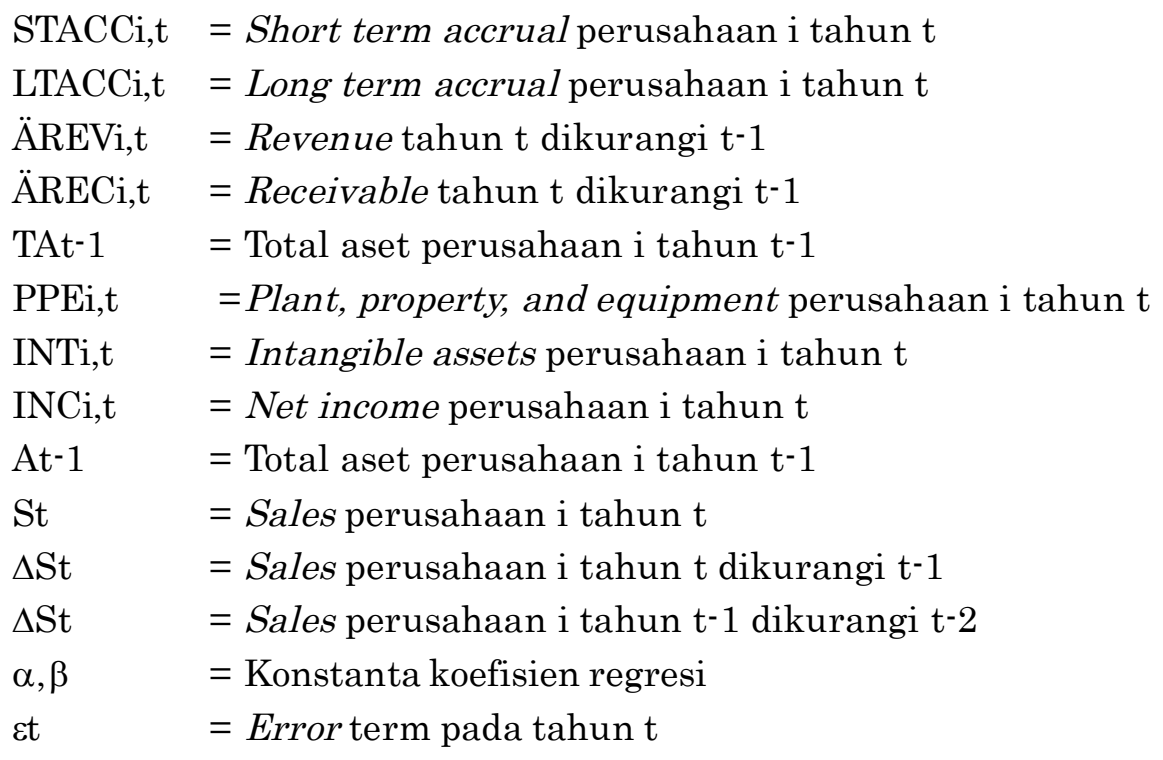

Variabel independen terdiri dari ukuran Komite Audit, independensi Komite Audit, keahlian Komite Audit, dan rapat Komite Audit. Ukuran Komite Audit diukur secara numeral, yaitu berdasarkan jumlah individu yang berada dalam Komite Audit. Independensi Komite Audit diukur dengan menggunakan persentase, yakni membagi jumlah Komite Audit independen dengan total Komite Audit. Keahlian Komite Audit juga diukur dengan menggunakan persentase, yakni membagi jumlah Komite Audit yang berlatar belakang keuangan dan akuntansi dengan total Komite Audit. Rapat Komite Audit diukur secara numeral, yaitu berdasarkan jumlah rapat atau pertemuan yang dilakukan oleh Komite Audit dalam jangka waktu setahun.

\section{Model Empiris}

Penelitian ini menggunakan analisis regresi linier sederhana untuk menguji hipotesis 1 (H1). Model regresi untuk menguji $\mathrm{H} 1$ adalah sebagai berikut; $\mathrm{EM}=\alpha_{0}+\beta_{1}$ DUM_EPS $+\varepsilon \mathrm{t}$

Pengujian hipotesis 2 sampai dengan 5 (H2-H5) menggunakan Analisis Regresi Berganda. Model regresi untuk menguji $\mathrm{H} 2-\mathrm{H} 5$ adalah sebagai berikut; $\mathrm{EM}=\alpha_{0}+\beta_{1} \mathrm{UKA}+\beta_{2} \mathrm{IKA}+\beta_{3} \mathrm{KKA}+\beta_{4} \mathrm{RKA}+\varepsilon \mathrm{t}$ 


\section{Pengaruh Mekanisme Komite...} 806

\section{Keterangan:}

EM = Earning management yang diproksikan dengan SHORTDA, LONGDA, ABNCFO, ABNPROD, dan ABNDISCR

$\alpha, \beta=$ Konstanta koefisien regresi

DUM_EPS = Dummy earnings per share

ASI $\quad=$ Auditor spesialis industri

UKA $\quad=$ Ukuran Komite Audit

IKA $\quad=$ Independensi Komite Audit

KKA $=$ Keahlian Komite Audit

RKA = Rapat Komite Audit

$\varepsilon \quad=$ Error term

\section{HASIL DAN PEMBAHASAN}

\section{Manajer Melakukan Manajemen Laba untuk Menghindari Kerugian}

Analisis regresi linier sederhana digunakan untuk menguji hipotesis $1\left(\mathrm{H} 1 \mathrm{a}^{-}\right.$ H1e), yaitu manajer melakukan manajemen laba untuk menghindari kerugian. Pertama-tama dilakukan pengelompokan sampel menjadi dua kelompok, yaitu kelompok yang diduga melakukan manajemen laba dan yang tidak melakukan manajemen laba. Pengelompokan ini berdasarkan pada EPS. EPS yang digunakan dalam penelitian ini mengacu pada nilai tukar rupiah terhadap dolar Amerika (USD), seperti yang digunakan dalam penelitian Subekti (2012a), hal ini disebabkan karena sebagian besar investor di Indonesia berasal dari luar negeri. Batasan nilai EPS yang digunakan untuk membagi kelompok menjadi dua adalah $\mathrm{Rp} 573$, yaitu 5 persen dari kurs rata-rata 2012-2015 (Rp 11.453). Perusahaan yang diduga melakukan manajemen laba adalah perusahaan yang memiliki EPS antara nol sampai dengan Rp 573. Pengelompokkan sampel yang diduga melakukan manajemen laba dan yang tidak melakukan manajemen laba dapat dilihat pada tabel 2 berikut ini.

\begin{tabular}{ccc}
\hline Tahun & Teridentifikasi & Tidak Teridentifikasi \\
\hline 2012 & 69 & 14 \\
2013 & 73 & 10 \\
2014 & 72 & 11 \\
2015 & 72 & 11 \\
Total & 286 & 46 \\
\hline
\end{tabular}

Sampel yang teridentifikasi dan tidak teridentifikasi melakukan manajemen laba digunakan sebagai variabel dummy dalam pengujian hipotesis 1 , sampel yang teridentifikasi melakukan manajemen laba diberi nilai 1 dan 0 bagi perusahaan yang tidak teridentifikasi melakukan manajemen laba. Langkah selanjutnya adalah melakukan pengujian hipotesis $\mathrm{H} 1 \mathrm{a}-\mathrm{H} 1 \mathrm{e}$.

Ringkasan hasil analisis pengujian hipotesis 1 dapat dilihat pada tabel 3 . Dummy EPS signifikan untuk regresi ABNCFO dan ABNPROD, sedangkan dummy EPS tidak signifikan untuk SHORTDA, LONGDA, dan ABNDISCR. Koefisien dummy EPS untuk proksi ABNCFO adalah sebesar -0,132, hasil ini membuktikan bahwa manajer melakukan manajemen laba dengan cara memperkecil arus kas operasional untuk menghindari kerugian. Arah koefisien dari hasil penelitian H1c tidak sesuai dengan perumusan hipotesis yang menyebutkan bahwa manajer melakukan manajemen laba dengan cara memperbesar arus kas operasional untuk menghindari kerugian. Koefisien dummy EPS untuk proksi ABNPROD adalah 
sebesar 0,215, hasil ini mendukung hipotesis $1 \mathrm{~d}$ bahwa manajer melakukan manajemen laba dengan cara memperbesar biaya produksi untuk menghindari kerugian. Sebaliknya, dummy EPS untuk proksi SHORTDA, LONGDA, dan ABNDISCR adalah tidak signifikan, ini berarti terjadi penolakan hipotesis 1a, 1b, dan 1e.

Hasil ini menunjukkan bahwa manajer melakukan manajemen laba dengan mengelola arus kas operasional dan biaya produksi untuk menghindari kerugian. Manajer tidak melakukan manajemen laba terhadap transaksi-transaksi akrual jangka pendek dan jangka panjang, serta beban diskresioner. Temuan ini sesuai dengan Teori Prospek yang mengungkapkan bahwa keputusan yang diambil terkait keuntungun atau kerugian didefinisikan secara relatif pada suatu titik acuan (reference point). Manajer akan mengelola laba negatif yang berada dibawah titik nol agar menjadi laba positif dan berada diatas titik acuan (titik nol) (Hayn, 1995; Burgstahler \& Dichev, 1997; Subekti, 2012a).

\begin{tabular}{lccccc}
\hline & SHORTDA & LONGDA & ABNCFO & ABNPROD & ABNDISCR \\
\hline Konstanta & 0,016 & $-0,125$ & 0,617 & $-0,312$ & $-0,188$ \\
Dum_EPS & 0,016 & 0,004 & $-0,132^{* *}$ & $0,215^{* *}$ & $-0,059$ \\
& $(1,041)$ & $(0,313)$ & $(-6,297)$ & $(5,194)$ & $(-1,579)$ \\
F-value & 1,084 & 0,098 & $39,647^{* *}$ & $26,978^{* *}$ & 2,494 \\
Adj. $R^{2}$ & 0,000 & 0,003 & 0,105 & 0,073 & 0,004 \\
\hline
\end{tabular}

* Signifikan pada alpha 5\%

Keterangan: SHORTDA = Short Term Discretionary Accrual, LONGDA = Long Term Discretionary Accrual, ABNCFO = Abnormal Cash Flow From Operation, ABNPROD = Abnormal Production Cost, dan ABNDISCR = Abnormal Dicretionary Expense, Dum_EPS = Dummy Earnings per Share .

\section{Mekanisme Komite Audit dan Manajemen Laba}

Pengujian hipotesis selanjutnya dilakukan untuk menguji pengaruh pengaruh mekanisme Komite Audit (ukuran, independensi, keahlian, dan rapat) terhadap manajemen laba. Manajemen laba diproksikan dengan dua proksi, yaitu ABNCFO dan ABNPROD, kedua cara ini merupakan proksi yang digunakan oleh manajer untuk menghindari kerugian. Salah satu variabel independen, yaitu independensi Komite Audit dikeluarkan dalam penelitian karena memiliki data yang konstan selama tahun pengamatan.

\begin{tabular}{lcc}
\hline & ABNCFO & ABNPROD \\
\hline Konstanta & 0,510 & $-0,130$ \\
& $(7,592)$ & $(-1,064)$ \\
UKA & $-0,011$ & 0,026 \\
& $(-0,557)$ & $(0,723)$ \\
KKA & $-0,019$ & $-0,004$ \\
& $(-0,609)$ & $(0,068)$ \\
RKA & 0,000 & $-0,001$ \\
& $(-0,158)$ & $(-0,515)$ \\
F-value & 2,267 & 1,542 \\
Adjusted R & 0,017 & 0,008 \\
\hline
\end{tabular}

Tabel 3

Hasil Analisis Regresi Linier Untuk

Menguji Hipotesis 1

Tabel 4

Ringkasan Hasil

Pengaruh

Mekanisme Audit

terhadap Manajemen Laba

Hasil pengujian hipotesis $\mathrm{H} 2$ menunjukkan bahwa hipotesis tersebut tidak didukung. Hasil pengujian H2 menunjukkan bahwa ukuran Komite Audit tidak berpengaruh terhadap manajemen laba yang dilakukan dengan mengelola arus kas operasional (ABNCFO) dan biaya produksi (ABNPROD). Hal ini menunjukkan bahwa ukuran Komite Audit tidak berperan dalam menurunkan manajemen laba.

Hasil pengujian hipotesis $\mathrm{H} 4$ menunjukkan bahwa hipotesis tersebut tidak didukung. Hasil pengujian tersebut menunjukkan bahwa keahlian Komite Audit tidak berpengaruh negatif terhadap manajemen laba yang dilakukan dengan mengelola arus kas operasional (ABNCFO) dan biaya produksi (ABNPROD). Hal 


\section{Pengaruh Mekanisme Komite...}

808 ini menunjukkan bahwa besarnya jumlah anggota Komite Audit yang memiliki latar belakang keuangan dan akuntansi tidak berperan dalam menurunkan manajemen laba.

Hasil pengujian H5 menunjukkan bahwa hipotesis tersebut tidak didukung. Hasil pengujian tersebut menunjukkan bahwa rapat Komite Audit tidak berpengaruh negatif terhadap manajemen laba yang dilakukan dengan mengelola arus kas operasional (ABNCFO) dan biaya produksi (ABNPROD). Hal ini menunjukkan bahwa jumlah rapat yang diadakan oleh Komite Audit tidak dapat membatasi manajemen laba.

Hasil penelitian mengenai pengaruh mekanisme Komite Audit terhadap manajemen laba yang dilakukan dengan mengelola arus kas operasional dan biaya produksi tidak mendukung Jensen \& Meckling (1976) yang menyebutkan bahwa mekanisme tata kelola perusahaan merupakan mekanisme yang berperan dalam mekanisme monitoring untuk mengurangi biaya agensi, salah satunya yang timbul karena insentif manajer untuk mengelola laba. Mekanisme tata kelola perusahaan yang salah satunya tercermin dalam mekanisme Komite Audit bukan merupakan mekanisme yang dapat menurunkan manajemen laba di Indonesia.

Faccio \& Lang (2002) menemukan bahwa hampir di semua Negara terjadi konsentrasi kepemilikan perusahaan. Indonesia merupakan Negara yang kepemilikannya juga terkonsentrasi pada pemegang saham pengendali. Pemegang saham pengendali dalam struktur kepemilikan ini biasanya memegang posisi yang kuat untuk mempengaruhi direksi, sehingga perusahaan ini mungkin memiliki tata kelola perusahaan yang lebih rendah karena pemantauan yang tidak efektif oleh dewan (Wang, 2006). Hal inilah yang menyebabkan mekanisme Komite Audit tidak berperan dalam menurunkan manajemen laba, sebab pemegang saham pengendali dan direksi memiliki kedudukan yang kuat dalam menjalankan perusahaan. Direksi biasanya memiliki kedudukan yang cenderung sangat kuat, bahkan ada direksi yang tidak bersedia untuk memberikan informasi memadai kepada komisaris. Hal tersebut menyebabkan Komite Audit memiliki keterbatasan dalam melakukan pengawasan, sehingga akan membatasi kemampuan Komite Audit dalam menurunkan manajemen laba. Agustia (2013) juga mengungkapkan bahwa terdapat kendala yang cukup menghambat kinerja komisaris, termasuk didalamnya Komite Audit, yaitu masih lemahnya kompetensi dan integritas mereka. Hal ini terjadi karena pengangkatan komisaris biasanya didasarkan pada penghargaan, hubungan keluarga, atau hubungan dekat lainnya, padahal integritas dan independensi merupakan hal yang fundamental agar tata kelola perusahaan dapat terwujud secara efektif.

\section{SIMPULAN, KETERBATASAN, DAN SARAN}

\section{Simpulan}

Penelitin ini berfokus pada perusahaan yang melakukan manajemen laba untuk menghindari kerugian. Penelitian ini menemukan bahwa sebagian perusahaan di Indonesia melakukan manajemen laba dengan cara memperkecil arus kas operasional dan memperbesar biaya produksi untuk menghindari kerugian. Manajer tidak melakukan manajemen laba dengan mengelola aktivitas akrual jangka pendek dan panjang, serta beban diskresioner untuk menghindari kerugian. Manajer akan mengelola laba negatif yang berada dibawah titik acuan (titik nol) agar menjadi laba positif dan berada diatas titik acuan. Hal ini dilakukan karena kerugian sekalipun dalam jumlah yang kecil merupakan sinyal yang menunjukkan bahwa kinerja manajer buruk.

Penelitian ini juga memberikan bukti empiris bahwa mekanisme Komite Audit yang terdiri dari ukuran Komite Audit, keahlian Komite Audit, dan rapat Komite Audit tidak berpengaruh negatif terhadap manajemen laba yang dilakukan dengan 
mengelola arus kas operasional dan biaya produksi. Independensi Komite Audit dikeluarkan dari model penelitian karena memiliki nilai yang konstan selama tahun pengamatan. Ukuran, keahlian, dan rapat Komite Audit tidak dapat membatasi manajemen laba yang dilakukan perusahaan. Hal tersebut karena direksi biasanya memiliki kedudukan yang cenderung sangat kuat, bahkan ada direksi yang tidak bersedia untuk memberikan informasi memadai kepada komisaris. Hal tersebut menyebabkan Komite Audit memiliki keterbatasan dalam melakukan pengawasan, sehingga akan membatasi kemampuan Komite Audit dalam menurunkan manajemen laba.

\section{Keterbatasan dan Saran}

Penelitian ini hanya berfokus pada sektor manufaktur. Hal ini disebabkan karena salah satu model pengukuran manajemen laba hanya dapat diaplikasikan pada sektor manufaktur, yaitu model untuk mengukur abnormal production cost yang menggunakan data biaya produksi. Penelitian ini juga berfokus pada perusahaan yang melakukan manajemen laba untuk menghindari kerugian.

Penelitian selanjutnya diharapkan dapat mengembangkan model pengukuran manajemen laba yang dapat diaplikasikan ke semua sektor industri. Pengembangan model pengukuran tersebut dapat meningkatkan generalisasi hasil pene-

litian. Penelitian selanjutnya juga dapat berfokus pada perusahaan yang melakukan manajemen laba untuk tujuan yang lain, misalkan berfokus pada perusahaan yang melakukan manajemen laba saat melakukan penawaran saham perdana atau initial public offering (IPO).

\section{DAFTAR PUSTAKA}

Aditama, F. \& Purwaningsih, A. Pengaruh Perencanaan Pajak terhadap Manajemen Laba pada Perusahaan Non-manufaktur yang Terdaftar di Bursa Efek Indonesia. MODUS, Vol. 6, No. 1, 2014, pp. 33-50.

Agustia, D. 2013. Pengaruh Faktor Good Corporate Governance, Free Cash Flow, dan Leverage Terhadap Manajemen Laba. Jurnal Akuntansi dan Keuangan, Vol. 15, No. 1, pp. 27-42.

Anonim. Saham Inovisi dibekukan Empat Bulan karena Laporan Keuangan Banyak Salah. http://finance.detik.com, 2015. Access on 11 Mei 2017.

Alzoubi, E. S. S. \& Selamat, M. H. The Effectiveness of Corporate Governance Mechanisms on Constraining Earning Management: Literature Review and Proposed Framework. International Journal of Global Business, Vol. 5, No. 1, 2012, pp. 17-35.

Ayemere, A. C. \& Elijah, A. Audit Committee Attributes and Earnings Management: Evidence from Nigeria. International Journal of Business and Social Research, Vol. 05, No. 04, 2015, pp. 14-23.

Burgstahler, D. \& Dichev, I. Earnings Management to Avoid Earnings Decreases and Losses. Journal of Accounting and Economics, Vol. 24, 1997, pp. 99-126.

Carcello, J. V., Hermanson, D. R., Neal, T. L., \& Riley JR, R. A. 2002. Board Characteristics and Audit Fees. Contemporary Accounting Research, Vol. 19, No. 3, 2002, pp. 365-384.

Chandrasegaram, R., Rahimansa, M. R., Rahman, K. A., Abdullah, S., \& Mat, N. N. 2013. Audit Committee Characteristics on Earnings Management in $\mathrm{Ma}^{-}$ laysian Public Listed Companies. International Journal of Finance and Accounting, Vol. 2, No. 2, 2013, pp. 114-119.

Cohen, D. A. \& Zarowin, P. Accrual-based and Real Earnings Management Activities Around Seasoned Equity Offerings. Journal of Accounting and Economics, Vol. 50, No. 1, 2010, pp. 2-19. 
Pengaruh Mekanisme Komite...

810
Dechow, P. M. \& Skinner, D. J. Earning Management: Reconciling the Views of Accounting Academics, Practitioners, and Regulators. Accounting Horizon, Vol. 14, No. 2, 2000, pp. 235-250.

Faccio, M. \& Lang, L.H.P. 2002. The Ultimate Ownership of Western European Corporations. Journal of Financial Economics. Vol. 65, pp. 365-395.

Forum for Corporate Governance in Indonesia. Peranan Dewan Komisaris dan Komite Audit dalam Pelaksanaan Corporate Governance (Tata Kelola Perusahaan). Jakarta: FCGI. 2001.

Febriyanti, A., Sawarjuwono, T., \& Pratama, B. A. Manajemen Laba: Pro-Kontra Pemaknaan antara Kreditur dan Debitur dalam Proses Pembiayaan Kredit. Jurnal Manajemen dan Kewirausahaan, Vol. 16, No. 1, 2014, pp. 55-68.

Ferdawati. Pengaruh Manajemen Laba Riil Terhadap Nilai Perusahaan. Jurnal Akuntansi dan Manajemen, Vol. 4, No. 1, 2009, pp. 59-74.

Graham, J.R., Harvey, C.R., \& Rajgopal, S. The Economic Implications of Corporate Financial Reporting. Journal of Accounting and Economics, Vol.29, 2005, pp. 287-320.

Gunny, K. The Relation Between Earnings Management Using Real Activities Manipulation and Future Performance: Evidence from Meeting Earnings Benchmarks. Contemporary Accounting Research, Vol. 27, No. 3, 2010, pp. 855-888.

Hayn, C. The Information Content of Losses. Journal of Accounting and Economics, Vol. 20, 1995, pp. 125-153.

Jensen, M. C. \& Meckling, W.H. Theory of The Firm: Managerial Behaviour, Agency Cost and Ownership Structure. Journal of Financial Economics, Vol. 3, 1976, pp. 305-360.

Kothari, S. P., Leone, A. J., \& Wasley, C. E. Performance Matched Discretionary Accrual Measures. Journal of Accounting and Economics, Vol. 39, 2005, pp. 163-197.

Lestari, M. P. Pengaruh Grup Bisnis dan Praktik Ekspropriasi terhadap Manajemen Laba dengan Kepemilikan Keluarga sebagai Variabel Moderasi. Thesis. Brawijaya University, 2014.

Riduwan, A. Etika Perilaku Koruptif dalam Praktik Manajemen Laba: Studi Hermeneutika. Working Paper. STESIA Surabaya, 2010.

Roychowdhury, S. Earning Management Through Real Activities Manipulation. Journal of Accounting and Economics, Vol. 42, 2006, pp. 335-370.

Subekti, I. Accrual and Real Earning Management: One of the Perspective of Prospect Theory. Journal of Economics, Business, and Accountancy Ventura. Vol. 15, No. 3, 2012a, pp. 443-456.

Subekti, I. Real and Accruals Earning Management and Value Relevance of Accounting Information Among Indonesian Listed Companies. Disertasi. Universiti Sains Malaysia, 2012b.

Vajriyanti, E., Widanaputra, P., \& Putri, A. D. Pengaruh Manajemen Laba Riil pada Nilai Perusahaan dengan Good Corporate Governance sebagai Variabel Pemoderasi. Proceedings of National Symposium on Accounting XVIII, 2015.

Wang, D. 2006. Founding family ownership and earnings quality. Journal of Accounting Research, Vol. 44, pp. 619-656.

Wolnizer, P. W. Are Audit Committees Red Herrings?. ABACUS, Vol. 31, No. 1, 1995, pp. $45-66$.

Zang, A.Y. Evidence on the Trade-Off between Real Activities Manipulation and Accrual-Based Earnings Management. The Accounting Review, Vol. 87, No. 2, 2012, pp. 657-703.

Zhu, T., Lu, N., Shan, Y., \& Zhang, Y. Accrual Based and Real Activity Earning Management at the Back Door: Evidence from Chinese Reverse Mergers. $\mathrm{Pa}^{-}$ cific-Basin Finance Journal, Vol. 35, 2015, pp. 317-339. 